\title{
0 CARNAVAL DE URUGUAIANA NOS CIRCUITOS CARNAVALESCOS DOS PAMPAS \\ NOTAS SOBRE A ANÁLISE DA ECONOMIA ESTÉTICA DO ESPETÁCULO, 0 GLOBALISMO CULTURAL E A ANTROPOLOGIA DOS OBJETOS ENTRE CARNAVAIS
}

Ulisses Corrêa Duarte (UFRS)

O artigo apresenta o carnaval das escolas de samba de Uruguaiana e o contexto carnavalesco dos pampas no extremo sul do Brasil, a partir de um enfoque teóricometodológico que englobe as relações entre carnavais $e$ indique diferentes caminhos de análises. As configurações culturais dos carnavais permitiam a discussão acerca da forma global das escolas de samba, da expansão do modelo carioca e de um suposto paradigma vigente. As teorias do globalismo, conjuntamente com a teoria dos objetos, serão propostas, no intuito de abrir um leque de reflexões acerca dos fluxos materiais e simbólicos nesses circuitos, assim como os encontros, as interconexões e as negociações entre os carnavais dos pampas e do Rio de Janeiro.

CARNAVAL DE URUGUAIANA; ESCOLAS DE SAMBA; GLOBALISMO; CONFIGURAÇÕES CULTURAIS; TEORIA DOS OBJETOS; ESPETÁCULO.

DUARTE, Ulisses Corrêa. O carnaval de Uruguaiana nos circuitos carnavalescos dos pampas: notas sobre a análise da economia estética do espetáculo, o globalismo cultural e a antropologia dos objetos entre carnavais. Textos escolhidos de cultura e arte populares, Rio de Janeiro, v.12, n.2, p. 131-151, nov. 2015. 


\section{THE URUGUAIANA CARNIVAL IN THE CARNIVAL CIRCUITS OF THE PAMPAS}

\section{NOTES ON THE ANALYSIS OF AESTEHTIC ECONOMICS OF THE SHOW, GLOBALISM CULTURAL AND ANTHROPOLOGY OF OBJECTS BETWEEN CARNIVALS}

Ulisses Corrêa Duarte (UFRS)

The article presents the carnival of Uruguaiana samba schools and the carnival context of the pampas in southern Brazil, from a theoretical and methodological approach, encompassing relations between carnivals and indicating different paths for analysis. Cultural settings of carnivals allowed the discussion on the overall format of samba schools, the expansion of Rio's model, and an alleged current paradigm. The theories of globalism, together with the theory of objects, will be summoned in order to open up a range of reflections on the material and symbolic flows in those circuits, as well as meetings, interconnections and negotiations between the carnaval of the pampas and the one from Rio de Janeiro.

URUGUAIANA CARNIVAL; SAMBA SCHOOLS; GLOBALISM; CULTURAL SETTINGS; THEORY OF OBJECTS; SPECTACLE.

DUARTE, Ulisses Corrêa. O carnaval de Uruguaiana nos circuitos carnavalescos dos pampas: notas sobre a análise da economia estética do espetáculo, o globalismo cultural e a antropologia dos objetos entre carnavais. Textos escolhidos de cultura e arte populares, Rio de Janeiro, v.12, n.2, p. 131-151, nov. 2015. 
A cidade de Uruguaiana ${ }^{1}$ está localizada no extremo sul do Brasil, no oeste do Rio Grande do Sul, na fronteira entre três países: Brasil, Uruguai e Argentina. A tríplice fronteira que limita politicamente esses três países é recortada pelo caudaloso Rio Uruguai. O município de Uruguaiana faz fronteira fluvial com a cidade argentina de Paso de Los Libres (pela Ponte Internacional Getúlio VargasAgustín Justo), e sua zona rural ao sul se estende a municípios do Uruguai, a cerca de $80 \mathrm{~km}$ de seu centro urbano. Nesses limites, a divisão administrativa do estado mais meridional brasileiro também classificava essa região em que se situa Uruguaiana como o "Pampa gaúcho", "Fronteira Oeste"2 ou "Campanha".

O pampa enquanto bioma natural que se espalha entre os três países - e Uruguaiana está no centro espacial desse tipo de vegetação e clima - tem por características socioeconômicas as atividades ligadas à exploração agropastoril, em especial a criação de gado e a plantação de arroz. O município tinha o sexto maior rebanho bovino do estado e foi considerado o maior produtor de arroz do Rio Grande do Sul, com grande destaque nacional nessas produções. ${ }^{3}$

Historicamente, a região foi cenário de disputas territoriais frequentes entre as Coroas espanhola e portuguesa no período colonial, entre os séculos XVI e XIX. Foram inúmeros os tratados de definições de limites e as guerras de conquista. A importante localização geográfica de Uruguaiana, às margens do Rio Uruguai, que desemboca na bacia do Prata, ligando o interior do continente ao Oceano Atlântico e podendo chegar por vias fluviais às importantes capitais do sul (Montevidéu, no Uruguai, e Buenos Aires, na Argentina), fez com que a cidade fosse considerada ponto estratégico de resguardo territorial, vigilância armada e entreposto comercial ao sul do Brasil.

As longas planícies pontuadas por colinas pouco acentuadas e os horizontes distantes e pouco habitados ao longo do sinuoso caminho pela estrada BR290, a principal forma de chegar à cidade, não nos permitiam imaginar o cenário de efervescência social e de intensificação das atividades festivas durante as semanas que antecediam o carnaval local. Para a sua realização, uma série de negociações acumuladas nos abria um dinâmico circuito de indivíduos e objetos em circulação, indicando um complexo contexto de trocas entre Uruguaiana, os pampas e outras regiões do Brasil, que se conjugavam e interseccionavam na sua preparação para os desfiles competitivos (DUARTE, 2011).

Nos quatro anos consecutivos em que estive em Uruguaiana e nas cidades vizinhas circunscritas à região dos pampas para acompanhar as festas carnavalescas, períodos que se estenderam de 15 a 60 dias de permanência entre 2011 e 2014, pude constatar ampla mobilização social entre suas populações: o carna- 
val era o evento com maior adesão e participação popular, independente de que lado estávamos na tríplice fronteira. ${ }^{4}$

Para os uruguaianenses, o carnaval era considerado a festa mais importante e esperada do ano, assim como comportava o maior evento organizado pelo Poder Público e com maior investimento em subsídios e infraestrutura montada. Também era período de grande expectativa do setor turístico e comercial na cidade. Em suma, o carnaval era tema bastante valorizado, se constituindo num jogo absorvente (GEERTZ, 1989) entre os grupos que disputavam o título da cidade, sendo intensamente vivenciado por todas as classes sociais, envolvendo direta ou indiretamente boa parte de seus habitantes e os visitantes que compareciam, independente de profissão, bairro de origem ou participação direta nas associações carnavalescas. ${ }^{5}$ O carnaval em Uruguaiana, e isso se estendia a outros municípios dos pampas ao longo da Fronteira, podia ser entendido como um fato social total (MAUSS, 2003), que marcava um período de contemplação e ampla participação da sociedade uruguaianense, no qual diferentes indivíduos e grupos que dele participavam se articulavam numa prática cultural incorporada como tradição social e historicamente estabelecida.

O objetivo deste artigo é apresentar ao leitor inicialmente o cenário sociocultural do carnaval de Uruguaiana numa breve análise antropológica e, a partir dele, refletir sobre algumas possibilidades teóricas que se abriram a partir da pesquisa dos carnavais das e nas fronteiras. ${ }^{6}$ Nos três pontos que se seguem serão expostas as seguintes perspectivas: o carnaval como investimento público e gestão da Prefeitura Municipal, assimilando discursividades ligadas à economia e à produção de um espetáculo visual para a promoção da cidade; o carnaval compreendido a partir do globalismo da cultura carnavalesca, que se reconfigura a partir do surgimento e expansão do paradigma carioca idealizado nas escolas de samba; e o intenso e importante circuito carnavalesco de trocas, que extrapolava os limites geográficos e compreendia um incessante fluxo de objetos que circulavam nesses contextos e que produziam outras dimensões e escalas para se pensar na festa, a partir dos objetos e das negociações entre carnavais.

\section{O CARNAVAL FORA DE ÉPOCA NOS PAMPAS: MERCANTILIZAÇÃO E ECONOMIA ESTÉTICA DO ESPETÁCULO}

Nos últimos anos, o carnaval de Uruguaiana era organizado em três noites de desfiles e em três grupos de divisão hierárquica para a competição. Eram eles, em ordem decrescente: as Escolas do Grupo Especial, as Escolas do Grupo de Acesso (quatro) e as Escolas do Grupo 2 (três). ${ }^{7}$ Uma grande rivalidade se concentrava entre as mais antigas e maiores vencedoras do carnaval de Uruguaiana, 
Os Rouxinóis (fundada em 1953) e a Cova da Onça (fundada em 1970). Elas eram as associações carnavalescas com maior projeção na cidade, atraindo maior contingente de torcedores e componentes. A Ilha do Marduque (fundada em 1977) entrou nessa briga na década de 1990, quando conseguiu vencer seus primeiros carnavais e desbancar a partir de então o revezamento quase exclusivo entre as duas maiores. ${ }^{8}$

De forma diferente da que estamos acostumados nos desfiles do centro do país, as escolas de samba do Grupo Especial de Uruguaiana desfilavam duas vezes, em dois dias de carnaval, ambos com julgamento. Algumas desfilavam pela primeira vez na quinta-feira, outras na sexta-feira. Todas repetiam seu segundo desfile no sábado. Já as do Grupo 2 e do Acesso desfilavam apenas uma vez, na quinta-feira e na sexta-feira, respectivamente. Esse formato com dois dias de desfiles era incomum nos principais carnavais brasileiros, em que as associações carnavalescas tinham apresentações únicas com apenas um julgamento a cada carnaval. $^{9}$

Outra característica fundamental para entendermos o carnaval de Uruguaiana era o fato de, desde 2005, ele ser comemorado fora da data do feriado carnavalesco nacional. Desde então, o carnaval de Uruguaiana tinha a data fixada no terceiro final de semana após o feriado oficial de carnaval do país. Em 2005, a associação carnavalesca Os Rouxinóis, na época pentacampeã, teve sua quadra interditada por ação judicial movida no Ministério Público devido a denúncias de vizinhos por transgredir o limite de produção de ruídos durante seus ensaios noturnos. A ação judicial produziu grande tensão na cidade, e a Liga das Escolas de Samba de Uruguaiana (a Liesu), entidade que organizava o carnaval na época, reuniu a maior parte das escolas que, em protesto, tinham decidido não desfilar no Carnaval de 2005.

A contenda foi parcialmente solucionada com um acordo entre as partes; paralelamente, uma lei municipal foi promulgada pelo novo prefeito, Sanchotene Felice, no começo do mandato, a tempo de se remarcar o carnaval para outra data. Naquele ano, os desfiles aconteceriam fora de época, provisoriamente. ${ }^{10} \mathrm{O}$ que poderia sugerir um retrocesso para o carnaval das escolas de samba, que tiveram sua festa transferida e realizada de forma improvisada, foi o primeiro passo para a inauguração de um modelo de carnaval com base na contratação de destaques do mundo do samba de outras cidades, e na compra de objetos carnavalescos para reciclagem e reutilização em Uruguaiana, o que voltaremos a debater no decorrer deste artigo.

O formato de produção carnavalesca em Uruguaiana, assentado na contratação de indivíduos de carnavais do centro do país (em geral do Rio de Janei- 
ro) e na compra de materiais e objetos de outras cidades, se estabeleceu desde 2005 como marco temporal de avultoso crescimento da festa em números, causando grande interesse por parte de profissionais do mundo do samba (LEOPOLDI, 1978) do centro do país. Numa análise histórica rigorosa, poderíamos destacar antigas formas de negociações entre carnavais existentes, fato também ressaltado por historiadores locais, o que de certa forma sempre foi realizado desde o surgimento das escolas de samba em diferentes contextos carnavalescos no país - mas com trocas bem mais esporádicas e em menor quantidade em relação aos circuitos de trocas tão influentes na atualidade, com marcada duração e em constante expansão na região dos pampas.

Em 2005, a Escola de Samba Os Rouxinóis contratou para seu desfile Neguinho da Beija-Flor como intérprete, e Valéria Valenssa como destaque de chão. ${ }^{11}$ Essas duas contratações foram as primeiras de dezenas de outros artistas, músicos, ritmistas, coreógrafos e celebridades que partiriam para Uruguaiana depois de suas atividades nos seus carnavais de origem. Isso alavancou Uruguaiana à fama de grande atração de sambistas e "estrelas" 12 do carnaval carioca para a cidade durante seu carnaval, com grande crescimento de sua visibilidade na mídia especializada e na atração de turistas nos anos posteriores, tanto do Rio Grande do Sul quanto dos países vizinhos. O mesmo formato de sucesso foi adaptado para outras cidades nos pampas, que passaram a transferir a data de seus carnavais por intermédio de suas ligas ou comissões organizadoras, em nítida tentativa de repetir o sucesso do maior evento da Fronteira. O slogan "o terceiro maior carnaval do país", como os organizadores gostavam de divulgar nos materiais de promoção do evento, virou marca publicitária e motivo de orgulho da população local, mesmo sob críticas e ceticismo à afirmação autoatribuída.

A ascensão do carnaval de Uruguaiana como uma festa que envolve o comércio, a rede hoteleira, um grande número de visitantes, atrações nacionais e um suposto aumento de circulação de recursos econômicos permite a seus organizadores, a Prefeitura Municipal em conjunto com as escolas de samba, promover um sistema de interpretação e legitimação do carnaval como um potencial social e econômico a ser explorado. A festa passa a ser lida publicamente como uma empresa cultural do município, como um espetáculo ligado à ideia de uma indústria cultural importante para o desenvolvimento social e econômico da cidade (CANCLINI, 2008).

Entendemos que para a realização de um grande evento como o carnaval, que consome vultuosos recursos, deva haver rigorosa concatenação de uma série de envolvimentos: individuais e sociais (práticas culturais de engajamento nas escolas de samba ao longo da história); políticos (organização, leis muni- 
cipais, articulações entre lideranças sobre regulamentos e verbas) e econômicos (estrutura física, contratações, trocas e negociações nos mercados carnavalescos entre associações carnavalescas, investimentos individuais e subsídios públicos). Chamamos de economia estética do espetáculo essa conjunção de fatores engendrados e entrelaçados que definem a legitimação social do evento ante a opinião pública, por critérios ligados à primazia do visual (CAVALCANTI, 1995): enquanto o carnaval fosse considerado belo plasticamente e com atrações trazidas de outras regiões, ele merecia ser visto e era autorizado por parte da sociedade uruguaianense. O carnaval das escolas de samba de Uruguaiana pretendia a cada ano reproduzir na Fronteira o luxo, a beleza plástica e a excelência técnica e artística carnavalesca, numa aproximação das principais características do carnaval do Rio de Janeiro como modelo paradigmático imaginado de festa, adaptado ao contexto local.

Os dados presentes na divulgação dos números da festa eram a dimensão preferida nos discursos de legitimação do carnaval, principalmente entre as lideranças políticas, que entendiam o crescimento dos valores investidos no evento como sinônimo de progresso e de racionalidade técnica quase intuitiva, em que, quase sempre, o aumento de recursos significava um espetáculo maior e maior retorno turístico e comercial. Insistimos, porém: a economia estética do espetáculo compreende mais do que apenas os índices referentes à circulação monetária, e isso por duas razões. Partimos do pressuposto de que mesmo a economia mais arraigada aos cálculos quantitativos está fortemente vinculada às práticas culturais que conjugam valores, estilos de vida e escolhas individuais dentro de um quadro sociocultural mais amplo e anterior (SAHLINS, 2003). Em segundo lugar, porque a ampla e sempre intrincada relação entre práticas e estruturas em esferas imaginadas como distintas não pode ser detalhadamente separada, mesmo para a análise, considerando as articulações híbridas entre os arranjos econômicos, políticos ou culturais que resultam na produção do evento (ZELIZER, 2005).

A necessidade de desenvolver o carnaval em consonância com a chave do turismo justificava os esforços e gastos da Prefeitura na festa com a justificativa de um ganho para o comércio e o incremento de uma "indústria do carnaval", que distribuísse renda e fomentasse o desenvolvimento econômico da cidade. O prefeito Sanchotene Felice em $2005^{13}$ garantia a melhoria na infraestrutura do evento para os próximos anos. Num dos encontros da Prefeitura para discutir o tema, ele afirmou: “O Poder Executivo investirá forte no carnaval, onde teremos uma boa iluminação, sistema de som e arquibancadas metálicas", e concluiu, "Agora temos que pensar na busca por turistas." ${ }^{14}$ 
Em 2013, a receita da venda dos cerca de 19.400 ingressos para as três noites de desfiles já havia sido alavancada para 1,8 milhão de reais (três vezes mais que há cinco anos), sendo que esse valor era dividido entre as escolas de samba. Os ingressos foram colocados à venda em junho de 2012, e mais da metade deles já haviam sido vendidos na primeira semana; ${ }^{15}$ a mesma fórmula de venda de ingressos no meio do ano seguiu nos anos posteriores. Cada escola de samba do Grupo Especial de Uruguaiana arrecadava cerca de 200 mil reais apenas em subsídios provenientes dos ingressos, segundo informações da Comissão de Carnaval da Prefeitura. A infraestrutura do sambódromo estava orçada em cerca de 1,5 milhão de reais, com os equipamentos licitados e contratados a partir dos procedimentos administrativos controlados diretamente pela Prefeitura.

A Prefeitura Municipal de Uruguaiana instituía, por decreto anual enviado pelo Gabinete do Prefeito no primeiro mês de cada ano, uma Comissão de Carnaval que tinha por objetivo exclusivo cuidar da organização da festa (direção artística, infraestrutura do sambódromo, regulamentos e júri da competição). Uma sede provisória era instalada próximo à Avenida Presidente Getúlio Vargas, principal via da cidade e na qual as estruturas provisórias do sambódromo eram montadas nos mais de 700 metros de pista de desfile.

O arquiteto Carlos do Canto era o presidente da Comissão de Carnaval e responsável pela estrutura do sambódromo (junto ao arquiteto Alexandre Giorgi), cargo que acumulava desde 2011. Além do projeto do sambódromo, do Canto havia sido contratado para elaborar a "engenharia financeira" do evento, já que a Liga das Escolas de Samba de Uruguaiana, tinha sido demovida da organização do evento pelo Prefeito. ${ }^{16}$ A comercialização dos ingressos passou a encargo da Prefeitura, assim como toda a organização do evento de 2010 por ação do prefeito Felice (comercialização de ingressos, júri avaliador, segurança, comercialização de espaços comerciais, patrocínios, organização da concentração e dispersão dos desfiles, etc.).

Para Carlos do Canto, a Comissão de Carnaval comprovou o fato de que o carnaval da cidade dependia inevitavelmente do município para acontecer devido a seu patrocínio majoritário, apesar das reclamações de seus detratores. Com o incremento nos cachês pagos às escolas, em tese, o espetáculo se tornaria mais qualificado. O patrocínio pulou de 50 mil reais em 2009 para cerca de 260 mil reais para cada escola de samba do Grupo Especial em 2013. Carlos comparava o carnaval da cidade com shows de grandes artistas nacionais e estrangeiros. Com o aumento do cachê desses artistas acreditava-se numa produção mais requintada, numa atração com melhor performance e num espetáculo mais bem elaborado, por isto, mais caro. O planejamento financeiro da Comissão esperava sempre 
entregar a cada ano cachê maior às escolas de samba, contratadas para produzir um show cada vez mais arrojado. Foi na sua gestão que a Comissão de Carnaval idealizou a setorização das arquibancadas do sambódromo, a escala de preços entre espaços mais nobres e mais populares, multiplicando assim gradativamente a receita de comercialização dos ingressos que acabaram aumentando os cachês das escolas de samba.

A festa tratada por Carlos do Canto nada tinha de irracional, de extravasamento coletivo, de desordem e liminaridade (TURNER, 2008). Da mesma forma, diferentemente do senso comum que inscrevia o carnaval como excesso e como dispêndio de forças e recursos, para o presidente da Comissão organizadora ele era tratado como evento extremamente planejado, racionalizado e administrado como uma empresa. Um modelo de gestão ligado aos números, planilhas, licitações e resultados. O carnaval admitido pela Comissão poderia ser esquadrinhado, e seus objetivos ajustados às necessidades de crescimento e manutenção de sua qualidade e de suas principais características: atender os anseios da comunidade carnavalesca de Uruguaiana e trazer turistas, conforme a capacidade da estrutura da cidade.

\section{GLOBALISMO E CULTURAS CARNAVALESCAS}

Uma reportagem de 2008, intitulada Música de Bebeto Alves faz Homenagem ao carnaval de Uruguaiana, ${ }^{17}$ expunha a narrativa de origem do carnaval da cidade: a chegada dos Fuzileiros Navais do Rio de Janeiro pós-Segunda Guerra Mundial em Uruguaiana, e a fundação das primeiras escolas de samba no carnaval local.

A reportagem indicava que no álbum Devoragem, do músico Bebeto Alves, lançado em 2008, havia uma composição, "Naval" (letra e música de sua autoria), que fazia uma homenagem ao que seria o início do circuito de trocas carnavalescas entre a ex-capital da República e o extremo sul do país. A faixa era considerada pelo músico um funk/milonga, numa "mistura de ritmos" de diferentes regiões. A música narrava as aventuras de um militar chamado Naval transferido do Rio de Janeiro para a Fronteira. Nesse local, ele consagrou o samba e a malandragem ao se adaptar à nova terra:

Fez tanta Escola / Que pra te encurtar a história / Quando chega fevereiro / E acende a luz da avenida. / Filho do mar / Carregando a sua flâmula / Sai na Cova, Rouxinóis / Vai na Ilha do Marduque. / Faz o Rio / Faz o Samba / Faz sambar a academia / Faz um truque / Passa bamba / E enche o povo de alegria. 
Bebeto Alves fazia na música explícita referência às narrativas do surgimento das escolas de samba em Uruguaiana, e citava as três principais Escolas da cidade na composição: Cova, Rouxinóis e Ilha do Marduque. Os Filhos do Mar eram reconhecidos pelos historiadores do carnaval de Uruguaiana como a primeira escola de samba fundada na cidade, uma novidade trazida pelos Fuzileiros Navais no início de 1950.

Assim como "Naval”, o samba em sua forma institucionalizada também se enraizou em Uruguaiana e seguiu sua sina de promover encontros num cenário de riqueza e complexidade cultural. O entrelaçamento dos locais pelas "culturas carnavalescas" em formação, produzidas e adaptadas em muitas regiões, promoviam um sentido global de identificação entre os indivíduos com base na apreciação, no conhecimento e no estilo de vida de uma forma cultural em comum: o carnaval das escolas de samba.

No estudo sobre a forma de organização institucionalizada das escolas de samba, temos que ressaltar a presença de características locais em cada cidade em que ocorre a festa nesse formato de disputa, em diálogo com as estruturas de organização das associações, formas de apresentação e elementos obrigatórios invariáveis. Se considerarmos os circuitos translocais perceberemos que as migrações carnavalescas acionam elementos compartilhados, além da circulação de saberes, técnicas e objetos, nos aproximando de uma forma global de escola de samba, como formato básico de organização e desfile, consensualmente admitido, independente da cidade que estamos referenciando. Há elementos obrigatórios e indispensáveis, normas e regulamentos comuns. Muitos desses elementos ligados a uma forma considerada global de escola de samba têm origem num modelo conceitual e ideal: o "paradigma carioca" das escolas de samba do Rio de Janeiro, um modelo de associação voltado para o carnaval desenvolvido a partir do final da década de 1920 naquela cidade, reificado enquanto fórmula ideal a ser reproduzida ao longo da história do carnaval desde então (CABRAL, 1996; MORAES, 1987; GOLDWASSER, 1975).

O carnaval das escolas de samba do Rio de Janeiro sempre era ponto plausível de comparação e idealização nos carnavais da Fronteira. A inserção de ideias e de práticas provenientes da festa do Rio de Janeiro não era fato recente nesse cenário. Ao longo da história do carnaval de Uruguaiana, como exemplo, o samba e as instituições carnavalescas ligadas a ele foram surgindo e se aprimorando na formação das escolas de samba e nas práticas carnavalescas muitas vezes extraídas de exemplos e informações obtidos na festa carioca, maior padrão de sucesso e prestígio alcançado no Brasil. 
Podemos considerar, enquanto recente momento-chave de consolidação desse modelo paradigmático em Uruguaiana, a contratação de toda a Comissão Julgadora do carnaval - desde 2007 - composta por indivíduos com trajetórias ligadas ao carnaval carioca (e na sua maioria, nascidos no Rio de Janeiro). Desde 2006, a forma de julgar do Rio de Janeiro já havia sido adaptada a Uruguaiana, com divisão dos jurados em três cabines de observação ao longo da avenida e notas de 8 a 10 com possibilidade de frações em décimos. Os quesitos de julgamento já eram os mesmos dez do Rio de Janeiro, ${ }^{18}$ com o acréscimo do décimo primeiro, o "abre alas", o primeiro carro alegórico, avaliado exclusivamente em Uruguaiana há muitos anos. O manual de jurados, indicando os quesitos e as formas de avaliá-los, era coerente com o texto e com as exigências cariocas, fazendo com que os critérios de julgamento fossem quase idênticos nas duas cidades, aproximando assim os juízos e as avaliações dos desfiles nos dois carnavais com quase total semelhança.

Outro ponto de comparação é a análise dos enredos ${ }^{19}$ das associações carnavalescas uruguaianenses. Os enredos desenvolvidos pelas escolas de samba de Uruguaiana seguiam a regra de outras cidades do Brasil ao narrar, na maioria das vezes, fatos, situações históricas, assuntos, personagens, lendas e instituições de âmbito nacional. Por isso, entre as três maiores escolas da cidade, tivemos desde 2005 enredos de assuntos que poderíamos classificar como nacionais: "Terra Brasilis, a metamorfose da Vida", dos Rouxinóis em 2006; "Povo brasileiro, a mistura que deu samba", dos Rouxinóis em 2009; "Brasilidade, um estado de espírito, um sentimento de amor" da llha do Marduque em 2007.

De lá para cá, poucos enredos desenvolveram temas locais e regionais, como os imigrantes, "Uruguaiana homenageia o imigrante vencedor e mostra ao mundo sua etnia", da Cova da Onça em 2007; o arroz, lavoura de grande importância econômica em Uruguaiana, "Arroz: do império do meio ao pampa gaúcho, o grão que vale ouro", da Cova da Onça em 2011. Nos despertam interesse de análise nos últimos anos, os enredos que homenagearam escolas de samba cariocas ou personagens do mundo do samba do Rio de Janeiro: em 2011, a Ilha do Marduque homenageou a Beija-Flor de Nilópolis com o enredo "O sonho do beija-flor". Em 2012, foi a vez da Cova da Onça homenagear Martinho da Vila com o enredo "Tem Kizomba na Avenida! Cova Canta Martinho, Show da Vila". E em 2013, a mesma escola homenageou a escola de samba carioca Acadêmicos do Salgueiro com o enredo "Duas paixões, num só coração".

As possibilidades de realizações de trocas na Fronteira, como a migração carnavalesca sazonal e as escolhas dos enredos que sugeriam identificações e formas de pertencimento do carnaval local em temas nacionais, nos indicavam a im- 
portância da dimensão da "translocalidade" nesses carnavais. A distância no tempo e no espaço dos locais em contato nos permitia refletir sobre a dinâmica temporal do cenário investigado, destacando através das culturas carnavalescas a viabilidade das análises de contextos e de personagens nas situações etnográficas vividas em diferentes escalas, num processo de negociação e tradução cultural incessante, que nunca se encerrava completamente (BHABHA, 2010).

Featherstone (1995) nos condicionou a pensar na ideia de cultura global a partir dos intensos fluxos que cruzavam as escalas e planos: dinheiro, bens, pessoas, imagens e informação, que não podia ser atada a realidades sociais e culturais coerentes, estáticas e ordenadas. O esforço do autor ligado a essa perspectiva, pretendia readequar a ideia de cultura em novos termos, buscando enfatizar aspectos das descontinuidades, a intertextualidade, a reflexividade, o descontrole do significante, a impossibilidade de totalizações e definições fechadas.

Em nossa análise do carnaval no contexto dos pampas, pretendíamos pensar o cenário a partir da noção de configuração cultural (GRímSON, 2011). Esse conceito nos permite um distanciamento das análises que preferem entender a situação de encontro de culturas em contato, em que as culturas significam homogeneidade prévia, com processos de trocas e de conflitos entre duas totalidades anteriores. Preferimos partir da noção de configuração cultural, para poder nos afastar de um determinado conceito de cultura que não compreende as desigualdades, as heteroglossias e os conflitos nas situações vivenciadas pelos grupos e indivíduos.

A configuração cultural em Grímson nos possibilita entender um espaço social em que há desigualdades de poder, tramas simbólicas compartilhadas, horizontes de possibilidades e historicidade. A ênfase recai sobre a heterogeneidade das situações, as possibilidades e os contextos específicos em que as tramas são costuradas e constantemente reconstruídas, permitindo, assim, pensar em sua instabilidade, mesmo com a viabilidade dos processos sociais e das sedimentações históricas existentes, nunca delimitáveis e fixos.

Configurações implicam diferenças e desigualdades de poder dentro de cada cultura e entre culturas. E os processos sociais dentro desse marco de produção de sentidos comuns, do jogo das significações entre indivíduos e instituições, nos permitiam pensar em constituições de hegemonia, abrindo, assim, a inescapável dimensão política em cada processo. Hegemonias nas configurações produziam fronteiras, mas como processos hegemônicos dinâmicos, históricos e instáveis. Migrações, trocas culturais, heterogeneidade tornaram inviáveis as interpretações das culturas como se fossem mundos distantes. As relações entre carnavais produziam fronteiras borradas, perspectivas híbridas, disputas simbóli- 
cas, questionamentos, readequações e reorganização constante das identidades e jogos de interesses, desde os mercantis aos simbólicos que devem ser levados em conta na investigação dos carnavais e dos circuitos carnavalescos.

\section{A TEORIA DOS OBJETOS NAS NEGOCIAÇÕES ENTRE CARNAVAIS}

Bens e trocas, produção e consumo lidos numa matriz cultural, e não apenas na dimensão econômica, fizeram parte das premissas clássicas de autores como Douglas e Isherwood (2004), Sahlins (2003) e Bourdieu (2010). Esses autores abriram um caminho nos estudos das ciências sociais com o foco da análise nas formas de consumo, no predomínio do valor de troca nos estudos dos grupos humanos, favorecendo uma abordagem alternativa aos estudos marxistas anteriores que davam ênfase ao valor de uso e à produção das mercadorias. Os autores que privilegiaram o estudo do consumo nos permitiram compreender de que forma os significados dos objetos (ou de suas partes), seus usos e trocas possibilitavam uma profunda compreensão das relações sociais a partir da dimensão sociocultural agregada.

Mais recentemente, Featherstone (1995) nos colocou a par dos estudos sobre a cultura de consumo e, no caso da sociedade contemporânea, a centralidade das mercadorias, comunicadoras simbólicas que operam dentro da esfera dos estilos de vida por elas estruturados. Discutindo as culturas carnavalescas na Fronteira, a análise de como os objetos eram produzidos, transformados em mercadorias com valores distintos, trocados, reformulados, reciclados ou descartados muito nos dizia a respeito do funcionamento de um "mercado carnavalesco". Mercado que apresentava funcionamento dinâmico ao relacionarmos redes de indivíduos e objetos em distintos contextos locais, comportando configurações culturais com base em circuitos de trocas pelo e no carnaval. Por isso, acreditamos que os carnavais não se produzem em espaços sociais limitados e restritos, em suma, nas cidades que promovem a festa. O carnaval das escolas de samba, para além do local de sua apresentação, se produz na relação entre carnavais, estando o global e a circulação de indivíduos e objetos no cerne de sua constituição. No estudo dos carnavais do pampas, isso ficava ainda mais nítido. Identificar e analisar os circuitos carnavalescos de trocas entre os contextos das escolas de samba é o enfoque mais importante da proposta teórico-metodológica que aqui refletimos.

Com Appadurai (2010), centralizamos a perspectiva nas coisas trocadas. Para o autor, o valor é concretizado tão somente no ato da troca de objetos, no contexto específico observado. Concentrar o interesse nos objetos, em vez de 
apenas nas formas e funções da troca, nos abriria a possibilidade de compor o vínculo entre a troca e o valor da coisa, enfatizando sua dimensão cultural em seu sentido mais amplo.

Ao refletir sobre as negociações entre carnavais, gerenciadas por indivíduos inseridos nas migrações carnavalescas entre o Rio de Janeiro e o sul do Brasil, em diferentes "contextos mercantis", ressaltamos a dimensão da translocalidade. Uruguaianenses das diretorias das escolas de samba frequentemente iam ao Rio para reuniões e compras, assim como, carnavalescos cariocas compravam em sua cidade e enviavam ao sul. Existiam casos de fluxos inversos, em que materiais eram comprados no sul - frequentemente no comércio de materiais carnavalescos do outro lado da Fronteira, onde eram mais baratos ou por se tratar de materiais não comercializados no Brasil - e enviados ao Rio de Janeiro (os carnavais das cidades brasileiras dos pampas compravam largamente materiais para confecção de carnaval, sobretudo plumas e pedrarias, em Paso de Los Libres, Argentina).

Para Appadurai (2010), o contexto mercantil é a variedade de arenas sociais, no interior de ou entre unidades culturais, que ajuda a estabelecer o vínculo entre a candidatura de uma coisa ao estado de mercadoria e a fase mercantil de sua carreira. É o ambiente social da mercadoria (seus regimes de valor, sua origem, sua materialidade) em conjunção com seu estado simbólico e temporal.

Segundo Kopytoff (2010), o que diferencia objeto e mercadoria é a fase de sua vida. Quando os objetos são destinados às trocas nos contextos mercantis, eles se transformam em mercadorias. Coisas ou objetos podem ser tratados como mercadorias em determinada ocasião, e não em outra. Por isso, subjacente à economia objetiva das transações visíveis, há a economia moral, que valoriza determinadas coisas em determinados contextos para a troca. Teremos aqueles objetos que podem ser descartados para a decomposição; e os objetos mercantilizáveis, que dependem de critérios individuais ou coletivos com base em crenças culturais de valor, de utilidade, origem; além dos objetos não suscetíveis às trocas, portanto, nunca transformados em mercadorias. O fluxo das mercadorias trocadas em sistemas mercantis abre a possibilidade do estudo das ordens valorativas das diferentes culturas; assim, para o autor, "o que é significativo sobre a adoção de objetos estrangeiros - e ideias estrangeiras - não é a de sua adoção, mas sim a maneira pela qual eles são culturalmente redefinidos e colocados em uso" (p. 93).

As relações interculturais entre carnavais diminuíam as distâncias entre as mercadorias e dinamizavam os quadros culturais que as classificavam. O conhecimento técnico para a fabricação, comportando um saber próprio da produção 
pelos seus contextos de aprendizado e pelas formas de fazer dos indivíduos responsáveis pelo seu invento (os profissionais de barracão, artesãos, costureiras), podia ser descortinado nas suposições de autenticidade e padronização das mercadorias em seus contextos e entre os contextos. Podemos também ressaltar, nas relações sociais que acumulavam esses conhecimentos, as suposições econômicas, sociológicas e culturais instauradas no interesse da criação de "mercados carnavalescos" paralelos aos centros de produção de carnaval, por seus produtores e consumidores, que abriam novos circuitos carnavalescos (no avanço dos contextos mercantis carnavalescos no sul do Brasil, no norte do Uruguai e nordeste da Argentina).

Seria possível pensar a mercantilização do carnaval dos desfiles das escolas de samba no país a partir do processo histórico de transformação dos objetos carnavalescos em mercadorias entre carnavais. Parte do desafio que trazemos para reflexão é a busca da "vida social das mercadorias" (suas biografias) através do método etnográfico, na definição de rotas relevantes e costumeiras, na construção cultural das mercadorias, nas mudanças de fluxos e nas biografias culturais desses objetos (de onde eles vêm e quem os fabricou, acumulação de contextos e donos, usos heterogêneos e transformações de significados).

Outra perspectiva interessante que poderia nos ajudar a pensar nos materiais de produção, nos objetos fabricados e nas mercadorias carnavalescas é a teoria das coisas, de Daniel Miller (2013). O autor demonstra que não só através das coisas as pessoas se representavam, com variáveis de gênero, classe, origem, níveis de educação, etc. A semiótica criticada por Miller queria dar conta dos objetos a partir da ideia de que os indivíduos davam representatividade às coisas, reduzindo-as às pessoas (nos mencionados estudos de Mary Douglas e Isherwood, assim como em Marshall Sahlins). Para o autor, nós, os humanos, também estamos entre as coisas. Nossos usos e identificações com a cultura material, a partir do entendimento de nossa humanidade, se ampliam quando entendemos que "as coisas também fazem as pessoas" (Miller, 2013, p. 66). A teoria da objetificação de Miller pretende dissolver as oposições entre pessoas e coisas.

Sua preferência pela dialética de Hegel, em que sujeitos e objetos vivem num processo dinâmico de produção, considerava que em Marx, mesmo que fortemente influenciado por aquele, as coisas se tornaram opressivas tomando caráter negativo. Em Marx, as mercadorias eram o fruto da economia de exploração e alienação capitalista, os instrumentos da opressão humana. A partir daí, pouca atenção se deu à questão da dialética da materialidade na cultura, componente intrínseca de todas as relações sociais, das morais às econômicas. Miller questiona o lugar subvalorizado das coisas nas ciências sociais. E defende a necessi- 
dade de colocá-las como algo comum, e isso não significa entronizá-las, mas torná-las parte necessária de nossa vivência e nosso entendimento na produção de nosso mundo particular.

Traduzindo Miller para nosso contexto mercantil carnavalesco, as coisas nas culturas do carnaval eram imprescindíveis porque produziam as relações sociais e a interculturalidade, não sendo seus meros resultados. Apesar da efemeridade do carnaval das escolas de samba (os desfiles de pessoas e coisas só ocorre num fim de semana por ano), os objetos utilizados no evento eram preparados ao longo de meses a fio de elaboração. Os objetos carnavalescos utilizados não eram apenas criados e negociados; também diziam coisas sobre a narrativa contada no enredo da escola de samba, além da conquista de prestígio social pelo indivíduo ou pelo grupo que os portava.

As coisas constituem as realidades individuais e coletivas, e recombinamse com outras coisas para além da manipulação e do controle dos grupos humanos. Os objetos têm vida própria, são celebrados, fazem história e podem ser reformulados a cada carnaval que passa. Não raro, esculturas e objetos são aplaudidos de pé nos sambódromos, tornando assim complexos os critérios de humanidade e inumanidade que dividem as coisas e as pessoas para a audiência. Pessoas anônimas podem portar coisas consagradas na festa, o que lhes concede posição social antes inacessível, para além do carnaval. Na vida social do carnaval, as coisas podem colocar os indivíduos em seus lugares, de estrelas e protagonistas da festa a situações de vexame e difamação (nos casos de objetos considerados de péssimo gosto ou com pouca durabilidade, nos casos de perdas ou avarias em meio ao trajeto do desfile). Os objetos carnavalescos têm vida própria, contêm biografias particulares e nos contam coisas sobre seus possuidores. Essa é a principal contribuição de Miller para o estudo dos objetos e que nos permite pensar em outros caminhos de reflexão teórica do carnaval.

\section{CONSIDERAÇÕES FINAIS}

O carnaval de Uruguaiana era o principal evento anual dos pampas e funcionava como um polo carnavalesco na região. Desde a fundação das primeiras escolas de samba, com a chegada dos fuzileiros navais na década de 1950, até quando, em 2005, os desfiles da cidade passaram a acontecer num calendário fora de época, esse cenário intercultural de encontros e negociações nos indicava a circulação de saberes, técnicas, indivíduos e objetos nos circuitos estabelecidos entre o carnaval carioca e o uruguaianense. O contexto carnavalesco dos pampas nos abria diferentes possibilidades de análise dos carnavais no Brasil com base na importante dimensão da translocalidade. 
Devemos também observar um vigoroso fluxo de mão de obra carnavalesca e de negociações de materiais e de objetos carnavalescos entre escolas de samba de cidades distintas nos pampas. Alegrete, Paso de Los Libres (Argentina), Artigas (Uruguai) fizeram parte de minha recente trajetória etnográfica, e seus carnavais farão parte de futuras análises sobre o tema. Esse circuito de trocas regionais comportava carnavais que de uma forma ou de outra fomentavam a expansão da forma global idealizada das escolas de samba ao longo do Rio Uruguai, com forte influência do modelo carioca enquanto paradigma. Os mercados carnavalescos se destacavam e se expandiam à medida que os circuitos carnavalescos de trocas se iam aprimorando e alongando suas redes de relações interpessoais e de negociações entre carnavais.

Ao mesmo tempo em que os carnavais da região dos pampas estavam inseridos em fronteiras enquanto aspectos delimitadores, como as físicas, políticas, culturais, históricas, simbólicas, identitárias, eles também estavam para além delas. As culturas se recusam a ser encurraladas nas fronteiras; elas transgridem seus limites (HALL, 2009). De acordo com nosso enfoque teórico-metodológico, as múltiplas fronteiras existentes se acomodavam e se atualizavam incessantemente em "configurações culturais" que extrapolavam os limites do local. As configurações culturais enfatizam os contextos e as heterogeneidades das práticas e das estruturas sociais (GRíMSON, 2011), e, sobretudo, as dimensões políticas nas disputas por hegemonias entre os grupos sociais.

Podemos investigar, através da etnografia dos carnavais das escolas de samba nas fronteiras e dos indivíduos participantes, os processos de hibridação conjecturados nos cruzamentos multiculturais (CANCLINI, 2008). Os mercados e circuitos de trocas de objetos nos possibilitavam interpretar as trajetórias e as situações vividas por nossos interlocutores, pensando nas teorias do globalismo, em que as trocas não constituíam homogeneização cultural, mas possibilitavam transformações dos modelos culturais dos carnavais ao longo da sua história. A perspectiva da "economia estética do espetáculo" contemplava a análise de um campo social e político, prático e discursivo, com base no evento definido por conceitos ligados a uma estrutura profissional de produção, com o aprimoramento estético que dele resultava, e uma expansão de mercados (introdução de novos saberes, técnicas e avanço da perspectiva econômica).

Para entender a produção dos carnavais, em sua definição intercultural a partir dos circuitos translocais, seria necessário abrir um eixo teórico de pesquisa pensando nos objetos. A antropologia dos objetos e da materialidade nos permite pensar nos mercados em expansão nos pampas. Ao analisar os objetos carnavalescos nos contextos mercantis, parte das negociações culturais e econômi- 
cas dos carnavais pode ser descortinada nesses encontros. Os regimes de valor, a forma de utilização dos objetos, sua vida útil e descarte, e o debate sobre os locais de confecção nos abrem como possibilidade refletir sobre os discursos de autenticidade e mercantilização dos carnavais (APPADURAI, 2010). Além da ideia de representação dos objetos, as pessoas e as coisas devem estar estabelecidas no mesmo estatuto de importância e de produção simbólica (MILLER, 2013).

Os carnavais das escolas de samba são constituídos pelos contextos locais, mas se entrecruzam globalmente, formando circuitos de trocas e circulação de indivíduos e objetos, abrindo novos caminhos e possibilidades nas discussões sobre diferenças e intersecções entre as culturas carnavalescas. A economia estética do espetáculo, os circuitos carnavalescos de trocas translocais e a reflexão sobre os objetos são eixos conceituais-chave para dar seguimento, numa outra perspectiva teórica, ao estudo do carnaval no Brasil e para além de seus limites territoriais.

\section{NOTAS}

1 Cidade média do Estado do Rio Grande do Sul, Uruguaiana tem população estimada em 125 mil habitantes, segundo dados do censo de 2010 do Instituto Brasileiro de Geografia e Estatística.

2 Quando a palavra fronteira for grafada com inicial maiúscula, estaremos indicando o contexto da pesquisa, a região da Fronteira Oeste do Rio Grande do Sul. Quando em minúscula, as fronteiras serão indeterminadas. O substantivo feminino neste caso terá significado amplo: fronteira física, geográfica, política, social ou cultural.

3 Segundo o Censo Agropecuário 2006 do Instituto Brasileiro de Geografia e Estatística (IBGE), eram cerca de 234 mil cabeças de gado. O índice de Lavoura Temporária de 2011 do IBGE mediu cerca de 734 mil toneladas de arroz (em casca) colhidas no ano. Disponível em http://cidades.ibge.gov.br/Acessado em 28/9/2013.

4 Eram muitas as cidades que tinham associações carnavalescas e promoviam desfiles competitivos embalados pelo samba como gênero musical de apresentação. Existiam diferenças de estrutura de desfile e de nomenclatura, mas a base formal de apresentação era similar à das escolas de samba cariocas. Além de Uruguaiana, chamavam atenção na região: no lado brasileiro os carnavais de Itaqui e Alegrete. Nos pampas argentinos, Paso de Los Libres, Monte Caseros e Corrientes. No Uruguai, Artigas e Bella Unión.

5 Para se ter uma ideia, considerando apenas o interesse dos meios de comunicação locais, as principais rádios tinham programas diários específicos sobre o 
carnaval, assim como os jornais da cidade divulgavam diariamente notícias relacionadas às escolas de samba e à preparação para a festa carnavalesca.

6 A discussão proposta neste artigo faz parte de uma pesquisa em andamento, articulada ao projeto de tese de doutorado em antropologia social do autor.

7 Eram seis escolas de samba no Grupo Especial de Uruguaiana em 2014: Unidos da Cova da Onça, Os Rouxinóis, Unidos da Ilha do Marduque, Bambas da Alegria, Deu Chucha na Zebra, Acadêmicos de São Miguel. No Grupo de Acesso: Apoteose do Samba, Império Serrano, Imperadores do Sol, Pantera Negra. No Segundo Grupo: Toca do Lobo, Unidos da Mangueira, Aliança do Samba. Havia um bloco afro convidado para a abertura do carnaval, que, entretanto, não participava das competições, o Aruanda.

8 A Escola de Samba Deu Chucha na Zebra foi a única entidade que quebrou duas vezes a sequência das consideradas grandes escolas de Uruguaiana (em 1980 e 1999). Hoje, a escola se reveza na posição intermediária, ficando longe dos resultados e do patamar de desfile das três citadas.

9 Em carnavais de muitas cidades - como Rio de Janeiro, São Paulo e Porto Alegre - as primeiras colocadas voltavam a desfilar no final de semana posterior ao desfile, dessa vez sem julgamento, no chamado "desfile das campeãs". Em Uruguaiana, não era programado esse tipo de desfile.

10 "Um projeto de lei resultou na modificação de uma Lei Municipal ambiental que prevê o aumento no limite de decibéis quando em eventos carnavalescos." (JORNAL DA CIDADE, 18/1/2005, p. 7).

11 Valéria Valenssa, a mulata que por anos a fio foi um dos ícones do carnaval carioca com a personagem Globeleza, protagonista da vinheta de divulgação do carnaval pela Rede Globo, detentora dos direitos de transmissão do Grupo Especial do carnaval dessa cidade. Neguinho da Beija-Flor é um dos intérpretes que cumpre função há mais tempo ao microfone de uma escola de samba carioca; desde 1976 ele é a voz oficial daquela que ele traz no nome.

12 Intérpretes como Wantuir, Nêgo, Wander Pires, Ciganerey, Igor Sorriso, Ito Melodia, Dominguinhos do Estácio; mestres de bateria como Marcão do Salgueiro e Casagrande da Unidos da Tijuca, carnavalescos como Cahê Rodrigues e Jaime Cezário, destaques como Ana Paula Evangelista, Viviane Araújo são apenas alguns dos nomes que já estiveram em Uruguaiana e na região dos pampas como mão de obra carnavalesca contratada desde então.

13 Foi Prefeito de Uruguaiana em dois mandatos, de 2005 a 2008 e de 2009 a 2012 (reeleito), pelo Partido da Social Democracia Brasileira (PSDB). $O$ atual prefeito, Luiz Schneider (PSDB), era vice-prefeito na segunda gestão de Felice.

14 Diário da Fronteira, 29 e 30/10/2005, p. 7. 
15 Os preços dos ingressos para os três dias de desfiles do carnaval de 2013 em Uruguaiana eram: camarote vip (coberto, 45 lugares, $\mathrm{R} \$ 13.500,00$ ); camarotes de 60 lugares (de $\mathrm{R} \$ 6.120,00$ a $\mathrm{R} \$ 9.000,00$ ); camarote de 40 lugares (de $\mathrm{R} \$ 4.080,00$ a $\mathrm{R} \$ 6.000,00)$; frisas (de $\mathrm{R} \$ 1.200,00$ a $\mathrm{R} \$ 3.000,00$ ); arquibancadas ( $R \$ 54,00$ por pessoa).

16 A disputa entre a Prefeitura Municipal e a Liesu se deu ao longo de 2009. Houve intensa troca de acusações e insatisfações provenientes dos dois lados veiculadas pela imprensa local, o que fez com que o prefeito afastasse a Liga das Escolas de Samba de Uruguaiana no carnaval de 2010. Não entrarei em detaIhes desse interessante episódio que envolve as questões políticas locais, já que demandaria um novo capítulo sobre o caso.

17 Jornal O Momento de Uruguaiana, 10 a 16/1/2008.

18 Eram eles: enredo, bateria, harmonia, samba-enredo, evolução, mestre-sala e porta-bandeira, fantasias, alegorias e adereços, comissão de frente e conjunto.

19 Ponto fundamental e obrigatório de qualquer desfile de escola de samba, o enredo é a narrativa selecionada previamente pela associação carnavalesca a cada ano (em geral, uma forma textual prévia), para ser contado com coerência nas suas expressões artísticas em desfile (fantasias, alegorias, alas, samba, coreografias, etc.).

\section{REFERÊNCIAS BIBLIOGRÁFICAS}

APPADURAI, Arjun. Introdução: mercadorias e a política de valor. In: A vida social das coisas: as mercadorias sob uma perspectiva cultural. Niterói: Editora da Universidade Federal Fluminense, 2010, p. 15-87.

BHABHA, Homi. O local da cultura. Belo Horizonte: Ed. UFMG, 2010.

BOURDIEU, Pierre. Razões práticas: sobre a teoria da ação. Campinas: Papirus, 2010.

CABRAL, Sérgio. As escolas de samba do Rio de Janeiro. Rio de Janeiro: Lumiar, 1996.

CANCLINI, Néstor Garcia. Culturas híbridas: estratégias para entrar e sair da modernidade. São Paulo: Ed. da Universidade de São Paulo, 2008.

CAVALCANTI, Maria Laura Viveiros de Castro. Carnaval carioca: dos bastidores ao desfile. Rio de Janeiro: Ed. da UFRJ, 1995.

DOUGLAS, Mary; ISHERWOOD, Baron. O mundo dos bens: para uma antropologia do consumo. Rio de Janeiro: Ed. UFRJ, 2004.

DUARTE, Ulisses Corrêa. O carnaval espetáculo no sul do Brasil: uma etnografia da cultura carnavalesca nas construções das identidades e nas transformações da festa em Porto Alegre e Uruguaiana. Dissertação (Mestrado) - Programa de Pós-graduação em Antropologia Social/UFRGS. Porto Alegre, 2011. 
FEATHERSTONE, Mike. Cultura de consumo e pós-modernismo. São Paulo: Studio Nobel, 1995.

GEERTZ, Clifford. A interpretação das culturas. Rio de Janeiro: LTC, 1989.

GOLDWASSER, Maria Júlia. O Palácio do Samba: estudo antropológico da Escola de Samba Estação Primeira de Mangueira. Rio de Janeiro: Zahar Ed., 1975.

GRíMSON, Alejandro. Los limítes de la cultura. Buenos Aires: Siglo Veinteuno Editores, 2011.

HALL, Stuart. Da diáspora: identidades e mediações culturais. Belo Horizonte: Ed. UFMG, 2009.

KOPYTOFF, Igor. A biografia cultural das coisas: a mercantilização como processo. In: APPADURAI, Arjun (Org.). A vida social das coisas: as mercadorias sob uma perspectiva cultural. Niterói: Editora da Universidade Federal Fluminense, 2010, p. 88-124.

LEOPOLDI, José Sávio. Escola de samba, ritual e sociedade. Petrópolis: Vozes, 1978.

MAUSS, Marcel. Ensaio sobre a dádiva. In: Sociologia e antropologia. São Paulo: Cosac Naify, 2003.

MORAES, Eneida de . História do carnaval carioca. Nova ed. rev. e ampl. Rio de Janeiro: Record, 1987.

MILLER, Daniel. Trecos, troços e coisas: estudos antropológicos sobre a cultura material. Rio de Janeiro: Zahar, 2013.

SAHLINS, Marshall. Cultura e razão prática. Rio de Janeiro: Zahar Ed., 2003.

TURNER, Victor. Dramas, campos e metáforas: ação simbólica na sociedade humana. Niterói: Ed. da UFF, 2008.

ZELIZER, Viviane. Intimité et economie. Terrain, n. 45, p. 13-28, 2005.

Ulisses Corrêa Duarte é doutorando do Programa de Pós-graduação em Antropologia Social da Universidade Federal do Rio Grande do Sul. Atualmente é pesquisador visitante do Goldsmiths College (University of London). Suas pesquisas se concentram nas áreas de antropologia urbana e econômica nos estudos das culturas populares, circulação de objetos e globalização.

Recebido em: 15/09/2014

Aceito em: 30/10/2014 
